\title{
Substitution of common concentrates with by-products modulated ruminal fermentation, nutrient degradation, and microbial community composition in vitro
}

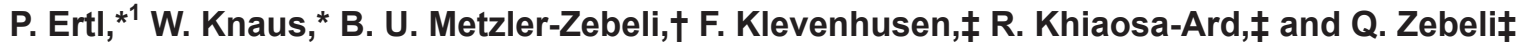 \\ *Department of Sustainable Agricultural Systems, Division of Livestock Sciences, BOKU—University of Natural Resources and Life Sciences, \\ 1180 Vienna, Austria \\ †Department for Farm Animals and Veterinary Public Health, Clinic for Swine, and \\ †Department for Farm Animals and Veterinary Public Health, Institute of Animal Nutrition and Functional Plant Compounds, \\ University of Veterinary Medicine, 1210 Vienna, Austria
}

\begin{abstract}
A rumen simulation technique was used to evaluate the effects of the complete substitution of a common concentrate mixture $(\mathrm{CON})$ with a mixture consisting solely of by-products from the food industry (BP) at 2 different forage-to-concentrate ratios on ruminal fermentation profile, nutrient degradation, and abundance of rumen microbiota. The experiment was a $2 \times 2$ factorial arrangement with 2 concentrate types (CON and $\mathrm{BP}$ ) and 2 concentrate levels (25 and $50 \%$ of diet dry matter). The experiment consisted of 2 experimental runs with 12 fermentation vessels each $(\mathrm{n}=6$ per treatment). Each run lasted for $10 \mathrm{~d}$, with data collection on the last $5 \mathrm{~d}$. The BP diets had lower starch, but higher neutral detergent fiber (NDF) and fat contents compared with CON. Degradation of crude protein was decreased, but NDF and nonfiber carbohydrate degradation were higher for the BP diets. At the 50\% concentrate level, organic matter degradation tended to be lower for $\mathrm{BP}$ and $\mathrm{CH}_{4}$ formation per unit of NDF degraded was also lower for BP. The BP mixture led to a higher concentration of propionate and a lower acetate-to-propionate ratio, whereas concentrations of butyrate and caproate decreased. Concentrate type did not affect microbial community composition, except that the abundance of bacteria of the genus Prevotella was higher for BP. Increasing the concentrate level resulted in higher degradation of organic matter and crude protein. At the higher concentrate level, total short-chain fatty acid formation increased and concentrations of isobutyrate and valerate decreased. In addition, at the $50 \%$ concentrate level, numbers of protozoa increased, whereas numbers of methanogens, anaerobic fungi, and fibrolytic bacteria decreased. No
\end{abstract}

Received November 4, 2014.

Accepted April 2, 2015.

${ }^{1}$ Corresponding author: paul.ertl@boku.ac.at interaction was noted between the 2 dietary factors on most variables, except that at the higher concentrate level the effects of $\mathrm{BP}$ on $\mathrm{CH}_{4}$ and $\mathrm{CO}_{2}$ formation per unit of NDF degraded, crude protein degradation, and the abundance of Prevotella were more prominent. In conclusion, the results of this study suggest that BP in the diet can adequately substitute $\mathrm{CON}$ with regard to ruminal fermentation profile and microbiota, showing even favorable fermentation patterns when fed at $50 \%$ inclusion rate.

Key words: Rusitec, by-product, concentrate, microbiota

\section{INTRODUCTION}

By-products from the food processing industry, such as various brans, middlings, oilseed meals, or beet pulp, have traditionally played an important role in the feeding of dairy cows as a substitute for grains and oil seeds in the diet. This substitution can lead to a highly improved edible feed conversion ratio in dairy cows (Ertl et al., 2015). Due to economic advantages, greater availability, lower human food versus animal feed competition, as well as low suitability for monogastric animals, the role of by-products in dairy cattle nutrition will further increase in the future. According to Bradford (1999), the by-products available worldwide would provide enough energy to support the production of 500 million tons of milk per year. Many studies have covered the topic of by-products as ruminant feeds (Durand et al., 1988; Mowrey et al., 1999; Hall and Chase, 2014), but only few experiments are available on mixtures of by-products as sole supplements in dairy cattle nutrition.

In a previous feeding trial, we tested the effects of a $100 \%$ substitution of a common concentrate mixture with a by-product mixture on feed intake, milk performance, blood variables, and the edible feed conversion ratio in organic dairy cow feeding (Ertl et al., 2015). 
In this earlier experiment, however, the consequences of including this by-product mixture in the diet on rumen fermentation and microbial community composition remained unclear. By-products, as opposed to traditional grains, are lower in starch but richer in fat or fiber. Due to these important nutrient shifts in the diet, it is not clear to which extent by-product feeding is reflected in the ruminal fermentation characteristics and abundance of the key microbiota in the rumen. Our hypothesis was that the substitution of common concentrates with a mixture of industrial by-products from the food processing would have substantial effects on the rumen fermentation profile, such as changes in short-chain fatty acid (SCFA) concentrations, composition and abundance of rumen microbiota, as well as gas formation. Therefore, the aim of the present study was to evaluate and quantify the effects of this substitution. For this, we chose a semicontinuous rumen simulation technique (Rusitec), with standardized similar rumen environmental conditions (i.e., temperature, $\mathrm{pH}$, buffer flow). As it is only a simulation of the rumen, conditions in the Rusitec system differ from in vivo conditions (e.g., lower digestibility, lower total SCFA concentrations, lower presence or lack of protozoa and significant shifts in the microbial population; Prevot et al., 1994; Martínez et al., 2010; Hristov et al., 2012). Thus, results from Rusitec have to be interpreted carefully if applied to in vivo conditions. However, as it is a standardized method, Rusitec allows for the investigation and relative comparisons among various feeding conditions (i.e., concentrate type and proportion in the diet; Khiaosa-Ard et al., 2015).

\section{MATERIALS AND METHODS}

\section{Diets}

Two different concentrate mixtures were tested at 2 different forage-to-concentrate ratios (75:25 and 50:50 on DM basis) with Rusitec. Concentrate and forage mixtures were obtained from our previous in vivo feeding trial (Ertl et al., 2015). The control concentrate mixture (CON) contained feeds commonly used in Austrian organic dairy cow feeding, whereas the experimental concentrate mixture (BP) consisted solely of industrial by-products, abundantly available in organic quality. Daily supply of feeds and the chemical composition of the different diets are shown in Table 1. The forage mixture was kept at 4 to $6^{\circ} \mathrm{C}$ after airdrying until the start of the experiment. Forage and concentrate mixtures were ground to pass through a 3-mm sieve before diet preparation. All experimental diets $(10 \mathrm{~g}$ of $\mathrm{DM})$ were prepared before the start of the first experimental run and stored at 4 to $6^{\circ} \mathrm{C}$.

\section{Experimental Procedure and Sampling}

The experiment, based on a $2 \times 2$ factorial arrangement with 2 concentrate types (CON and $\mathrm{BP})$ and 2 concentrate levels (25 and 50\%), consisted of 2 experimental runs, including all dietary treatments each time. Both runs comprised 12 fermenters $(\mathrm{n}=6$ per treatment) and lasted for $10 \mathrm{~d}$, with the final $5 \mathrm{~d}$ for data collection. For each run, ruminal fluid and solid digesta were collected randomly from 2 out of 8 nonlactating rumen-fistulated Holstein cows, housed at the Teaching and Research Farm Kremesberg of the University of Veterinary Medicine, Vienna, Austria. The ruminal fluid was filtered through 4 layers of medicinal gauze ( $\sim 1-\mathrm{mm}$ pore size) prior to inoculation, whereas the solid digesta of the same cows was collected and used unprocessed to inoculate the system (Khiaosa-Ard et al., 2015). Cows were fed hay ad libitum and were kept according to the Austrian guidelines for animal welfare (Federal Ministry of Health, 2004). The Rusitec apparatus and the experimental procedure were as described in Klevenhusen et al. (2015), except for a different infusion rate of artificial saliva of $328 \mathrm{~mL} / \mathrm{d}( \pm 6.9)$.

Fermenter fluid samples were collected daily from the open fermenters directly before exchanging of the feed bags, using a syringe equipped with a plastic tube. Part of the fluid samples was immediately analyzed for $\mathrm{pH}$, redox potential, and $\mathrm{NH}_{3}$ (Klevenhusen et al., 2015), whereas the other part was stored in separate tubes at $-20^{\circ} \mathrm{C}$ for determination of SCFA concentrations and analysis of microbiota composition. Daily fermentation gases of each fermenter were collected in gas-tight aluminum bags (Tecobag 8 L, Tesseraux Spezialverpackungen, Bürstadt, Germany).

\section{Laboratory Analyses}

Nutrient degradation was calculated from the difference between nutrient contents in the nylon bags before and after $48 \mathrm{~h}$ of incubation (feed residues from bags that were removed on sampling d 6-10 were pooled for each fermenter). After $48 \mathrm{~h}$ of incubation, feed bags were prepared and analyzed for DM, OM, CP, ether extract, and NDF corrected for ash (aNDFom) according to the methods and equipment presented in Klevenhusen et al. (2015). Nonfiber carbohydrates content was calculated as $\mathrm{NFC}=\mathrm{OM}-(\mathrm{CP}+$ ether extract + aNDFom). Determination of concentrations of SCFA (acetate, propionate, butyrate, isobutyrate, valerate, isovalerate, and caproate) in fermenter fluid was conducted via gas chromatography as described in detail in Klevenhusen et al. (2015). The $\mathrm{CH}_{4}$ and $\mathrm{CO}_{2}$ concentrations were measured using an infrared detector (ATEX Biogas Monitor Check BM 2000, Ansyco, 
Table 1. Daily supply of feeds and chemical composition of $\operatorname{diets}^{1}$ with $75: 25$ (25\%) and 50:50 (50\%) forage:concentrate ratios

\begin{tabular}{|c|c|c|c|c|}
\hline \multirow[b]{2}{*}{ Item } & \multicolumn{2}{|c|}{$25 \%$} & \multicolumn{2}{|c|}{$50 \%$} \\
\hline & $\mathrm{CON}$ & $\mathrm{BP}$ & $\mathrm{CON}$ & $\mathrm{BP}$ \\
\hline \multicolumn{5}{|l|}{ Supply ( $\mathrm{g}$ of DM/d per fermenter) } \\
\hline Total & 10.0 & 10.0 & 10.0 & 10.0 \\
\hline Alfalfa hay, first cut & 1.875 & 1.875 & 1.25 & 1.25 \\
\hline Grass silage, first cut & 5.625 & 5.625 & 3.75 & 3.75 \\
\hline Peas & 0.675 & - & 1.35 & - \\
\hline Maize & 0.5 & - & 1.0 & - \\
\hline Field beans & 0.5 & - & 1.0 & - \\
\hline Oats & 0.4 & - & 0.8 & - \\
\hline Wheat & 0.338 & - & 0.675 & - \\
\hline Maize middlings & - & 1.038 & - & 2.075 \\
\hline Beet pulp & - & 0.763 & - & 1.525 \\
\hline Rapeseed cake & - & 0.388 & - & 0.775 \\
\hline Soy cake & - & 0.225 & - & 0.45 \\
\hline Molasses & 0.075 & 0.075 & 0.15 & 0.15 \\
\hline Mineral and vitamin mix & 0.013 & 0.013 & 0.025 & 0.025 \\
\hline \multicolumn{5}{|c|}{ Chemical composition ( $\mathrm{g} / \mathrm{kg}$ of $\mathrm{DM})$} \\
\hline $\mathrm{OM}$ & 905.8 & 900.3 & 925.5 & 914.5 \\
\hline $\mathrm{CP}$ & 171.3 & 166.8 & 176.5 & 167.5 \\
\hline Crude fat & 28.5 & 37.3 & 27.0 & 44.5 \\
\hline aNDFom $^{2}$ & 369.8 & 394.5 & 299.5 & 349.0 \\
\hline $\mathrm{NFC}$ & 336.3 & 301.8 & 422.5 & 353.5 \\
\hline Starch & 130.3 & 82.0 & 260.5 & 164.0 \\
\hline Energy $\left(\mathrm{MJ}\right.$ of $\mathrm{NE}_{\mathrm{L}} / \mathrm{kg}$ of $\left.\mathrm{DM}\right)$ & 6.67 & 6.58 & 7.29 & 7.12 \\
\hline
\end{tabular}

${ }^{1}$ Concentrate type: $\mathrm{CON}=$ control concentrate; $\mathrm{BP}=$ by-product concentrate.

${ }^{2}$ Neutral detergent fiber corrected for ash.

Karlsruhe, Germany), and gas volume was obtained via the water displacement technique (Soliva and Hess, 2007).

\section{Genomic DNA Extraction and Quantitative PCR}

Prior to DNA extraction, fermenter fluid samples of the last 5 sampling days per fermenter and run were thawed at $4^{\circ} \mathrm{C}$, pooled, and homogenized. Total genomic DNA was extracted from about $300 \mu \mathrm{L}$ of homogenized fermenter fluid sample using the PowerSoil DNA isolation kit (MoBio Laboratories Inc., Carlsbad, CA), including a bead beating step with few modifications. Samples were incubated at $70^{\circ} \mathrm{C}$ for $10 \mathrm{~min}$ after addition of $\mathrm{C} 1$ buffer. The DNA elution volume was $100 \mu \mathrm{L}$. Primers were commercially synthesized (Eurofins MWG Operon, Ebersberg, Germany; Supplementary Table S1; http://dx.doi.org/10.3168/jds.20149063). Amplifications were performed on a Stratagene Mx3000P QPCR System (Agilent Technologies, Santa Clara, CA) using Brilliant II SYBR Green QPCR Low ROX master mix (Agilent Technologies) mixed with the selected primer set (Supplementary Table S1) at a concentration of $400 \mathrm{nmol}$ for each primer and $1 \mu \mathrm{L}$ of genomic DNA. Each amplification reaction was run in duplicate with a final volume of $25 \mu \mathrm{L}$. The amplification procedure included an initial denaturation step at $95^{\circ} \mathrm{C}$ for $10 \mathrm{~min}$, followed by 40 cycles of $95^{\circ} \mathrm{C}$ for $15 \mathrm{~s}, 60^{\circ} \mathrm{C}$ for $30 \mathrm{~s}$, and $72^{\circ} \mathrm{C}$ for $30 \mathrm{~s}$. To determine the specificity of the amplification, melting curves of PCR products were monitored and aliquots $(10 \mu \mathrm{L})$ of PCR products were analyzed by electrophoresis on a $2 \%$ agarose gel (wt/vol). Negative controls without template DNA were included in triplicate. Amplification efficiency was calculated according to the following equation: $E=10^{-1 / \text { slope }}$ (Supplementary Table S1).

For quantification of bacterial and archaeal $16 \mathrm{~S}$ rRNA and protozoal 18S rRNA gene copy numbers, standard curves were constructed using universal primers to amplify serial dilutions of purified PCR products from genomic DNA of the original rumen fluid of cows using the primer set $27 \mathrm{~F}-1492 \mathrm{R}$ for quantification of bacterial 16S rRNA gene, primer set P.SSU.-54f-P. SSu-1747r for protozoal 18S rRNA gene, primer set 109F-934R for archaeal 16 rRNA gene (Li et al., 2009; Metzler-Zebeli et al., 2013), and the primer sets for anaerobic fungi (Denman and McSweeney, 2006). Amplification included an initial denaturation step at $95^{\circ} \mathrm{C}$ for $5 \mathrm{~min}$, followed by 35 cycles of $95^{\circ} \mathrm{C}$ for $60 \mathrm{~s}, 52^{\circ} \mathrm{C}$ for $90 \mathrm{~s}, 72^{\circ} \mathrm{C}$ for $90 \mathrm{~s}$, and a final elongation at $72^{\circ} \mathrm{C}$ for 7 min. After amplification, PCR products per primer set $(\mathrm{n}=3)$ were pooled. The PCR products were purified using the QIAquick PCR purification kit (Qiagen, Hilden, Germany). The purified PCR product using the 
universal primer set 27F-1492R was used as standard for quantification of total bacteria, genus Prevotella and bacterial species (Supplementary Table S1; http:// dx.doi.org/10.3168/jds.2014-9063). After spectroscopic determination (ND-2000 spectrophotometer, Nanodrop Technologies, Wilmington, DE) of DNA concentration of the purified PCR product, the copy number of standard DNA molecules were calculated using the following equation: DNA (molecules $/ \mu \mathrm{L})=\left[6.02 \times 10^{23}\right.$ $($ molecules $/ \mathrm{mol}) \times$ DNA amount $(\mathrm{g} / \mu \mathrm{L})] /[\mathrm{DNA}$ length $(\mathrm{bp}) \times 660(\mathrm{~g} / \mathrm{mol}$ per bp)]. Standard curves ranged from $10^{7}$ to $10^{3}$ molecules $/ \mu \mathrm{L}$. The standard curves were plotted with the Mx Pro QPCR software version 4.10 (Agilent Technologies) and were identical to results obtained from linear regression of concentration against $\mathrm{C}_{\mathrm{T}}$ (cycle threshold). The copy number of total bacteria, total protozoa, total methanogens, and anaerobic fungi were determined by relating the $\mathrm{C}_{\mathrm{T}}$ values to standard curves. The final copy numbers per milliliter of incubation fluid of total bacteria, genus Prevotella, bacterial species, total protozoa, total methanogens, and fungi were calculated using the equation $(\mathrm{QM} \times C \times \mathrm{DV}) /(S$ $\times V)$, where QM was the quantitative mean of the copy number, $C$ was the DNA concentration of each sample, DV was the dilution volume of extracted DNA, $S$ was the DNA amount (ng) subjected to analysis, and $V$ was the weight of the sample $(\mathrm{g})$ subjected to DNA extraction (Metzler-Zebeli et al., 2013) and were corrected for the experimentally derived amplification efficiency (Stevenson and Weimer, 2007; Petri et al., 2013). Efficiency-corrected gene copies of target bacterial species and group were expressed as the percentage of $16 \mathrm{~S}$ rRNA gene copy numbers of target bacterial group and species relative to the $16 \mathrm{~S}$ rRNA gene copy numbers of the reference total bacterial primer set (Stevenson and Weimer, 2007), which were multiplied by 100 to obtain the percentage of a target gene of universal gene copies. The reference universal primer set used (Muyzer et al., 1993) was a nondegenerate, domain-level primer set that amplifies all eubacterial species.

\section{Statistical Analyses}

Mean values of the last $5 \mathrm{~d}$ of each experimental run were subjected to ANOVA using mixed procedure of SAS (Version 9.2, SAS Institute, Cary, NC). Concentrate level (25 and 50\%), concentrate type (CON and $\mathrm{BP}$ ), and their 2-way interactions were included as fixed effects, whereas fermenter and run were considered to be random effects. Degrees of freedom were estimated with Kenward-Roger method. Multiple comparisons among means were carried out by the Tukey's method and differences were declared significant at $P<$ 0.05. Correlations among variables were performed us- ing corr procedure of SAS (Version 9.2, SAS Institute, Cary, NC).

\section{RESULTS}

\section{Ruminal Fermentation, Gas Formation, and Nutrient Degradation}

Ruminal fermentation traits of fermenter fluid were not affected by concentrate type, but the higher concentrate level resulted in slightly decreased $\mathrm{pH}$ and ammonia content (Table 2). The redox potential remained constant, reflecting anaerobic fermentation conditions. Concentrate type did not affect total $\mathrm{CH}_{4}$ or $\mathrm{CO}_{2}$ production. However, when gas formation was calculated in milliliter per gram of degraded aNDFom, $\mathrm{BP}$ resulted in lower $\mathrm{CH}_{4}$ and $\mathrm{CO}_{2}$ production; this effect was more distinctive at the $50 \%$ concentrate level, as indicated with significant interaction effects (Figure 1). The higher concentrate level increased $\mathrm{CO}_{2}$ production, as well as $\mathrm{CH}_{4}$ and $\mathrm{CO}_{2}$ formation per gram of degraded aNDFom. Compared with CON, BP had positive effects on aNDFom and NFC degradation, whereas OM degradation tended to reduce, with a more distinct effect at the higher concentrate level (Figure 2). When the diet included 50\% concentrates, $\mathrm{OM}$ and fat degradability increased compared with diets containing 25\% concentrates. Degradation of aNDFom tended to reduce when fed the higher level of concentrates. We observed a strong interaction $(P$ $=0.005)$ between level and type of concentrate for $\mathrm{CP}$ degradation. Whereas the $50 \%$ concentrate level led to a higher $\mathrm{CP}$ degradation for $\mathrm{CON}$, it was slightly reduced for BP. Despite this interaction, results show that overall $\mathrm{CP}$ degradation in $\mathrm{BP}$ was lower compared with CON (Figure 2).

\section{SCFA Concentrations}

Short-chain fatty acid concentrations for fermenter fluid are shown in Table 3. The BP diets increased concentrations of propionate, whereas butyrate and caproate concentrations were reduced when compared with CON. As a result of the elevated propionate concentration, the acetate-to-propionate ratio was lower for the BP mixture. With the higher level of concentrates, total SCFA production increased over $6 \%$ in the fermenter fluid, whereas concentrations of isobutyrate and valerate were lower compared with the $25 \%$ concentrate level. We observed a strong negative correlation between the concentration of propionate and caproate (r $=-0.97, P<0.001, \mathrm{n}=24$ ) and a positive correlation between the concentration of acetate and caproate $(\mathrm{r}=$ $0.68, P<0.001, \mathrm{n}=24)$. 
Table 2. Effects of concentrate type and level $(25$ or $50 \%)$ on fermentation traits, in vitro gas formation, and nutrient degradation $(\mathrm{n}=6$ per treatment, averages of $6-10)^{1}$

\begin{tabular}{|c|c|c|c|c|c|c|c|c|}
\hline \multirow[b]{2}{*}{ Item } & \multicolumn{2}{|c|}{$25 \%$} & \multicolumn{2}{|c|}{$50 \%$} & \multirow[b]{2}{*}{ SEM } & \multicolumn{3}{|c|}{$P$-value } \\
\hline & $\mathrm{CON}$ & BP & $\mathrm{CON}$ & $\mathrm{BP}$ & & Type & Level & Interaction \\
\hline $\mathrm{pH}$ & 6.95 & 6.95 & 6.84 & 6.90 & 0.08 & 0.112 & $<0.001$ & 0.060 \\
\hline Ammonia (mmol/L) & 14.2 & 13.2 & 12.9 & 12.7 & 2.2 & 0.161 & 0.053 & 0.380 \\
\hline Redox potential (mV) & -235 & -253 & -256 & -236 & 26 & 0.860 & 0.836 & 0.042 \\
\hline \multicolumn{9}{|l|}{ In vitro gas formation } \\
\hline $\mathrm{CH}_{4}(\mathrm{~mL} / \mathrm{g}$ of degraded $\mathrm{OM})$ & 2.1 & 2.1 & 2.2 & 2.0 & 0.21 & 0.709 & 0.771 & 0.625 \\
\hline $\mathrm{CO}_{2}(\mathrm{~mL} / \mathrm{g}$ of degraded $\mathrm{OM})$ & 11.2 & 11.1 & 13.3 & 12.4 & 1.21 & 0.600 & 0.139 & 0.734 \\
\hline $\mathrm{CH}_{4}\left(\mathrm{~mL} / \mathrm{g}\right.$ of degraded aNDFom $\left.{ }^{2}\right)$ & 11.8 & 9.2 & 19.1 & 11.2 & 1.43 & $<0.001$ & $<0.001$ & 0.033 \\
\hline $\mathrm{CO}_{2}(\mathrm{~mL} / \mathrm{g}$ of degraded aNDFom $)$ & 64.8 & 49.4 & 115.3 & 68.0 & 3.29 & $<0.001$ & $<0.001$ & 0.024 \\
\hline \multicolumn{9}{|l|}{ Nutrient degradation ( $\mathrm{g} / \mathrm{g}$ of supply) } \\
\hline $\mathrm{OM}$ & 0.585 & 0.584 & 0.639 & 0.617 & 0.006 & 0.057 & $<0.001$ & 0.079 \\
\hline $\mathrm{CP}$ & 0.697 & 0.675 & 0.737 & 0.671 & 0.008 & $<0.001$ & 0.015 & 0.005 \\
\hline
\end{tabular}

${ }^{1}$ Concentrate type: $\mathrm{CON}=$ control concentrate; $\mathrm{BP}=$ by-product concentrate.

${ }^{2}$ Neutral detergent fiber corrected for ash.

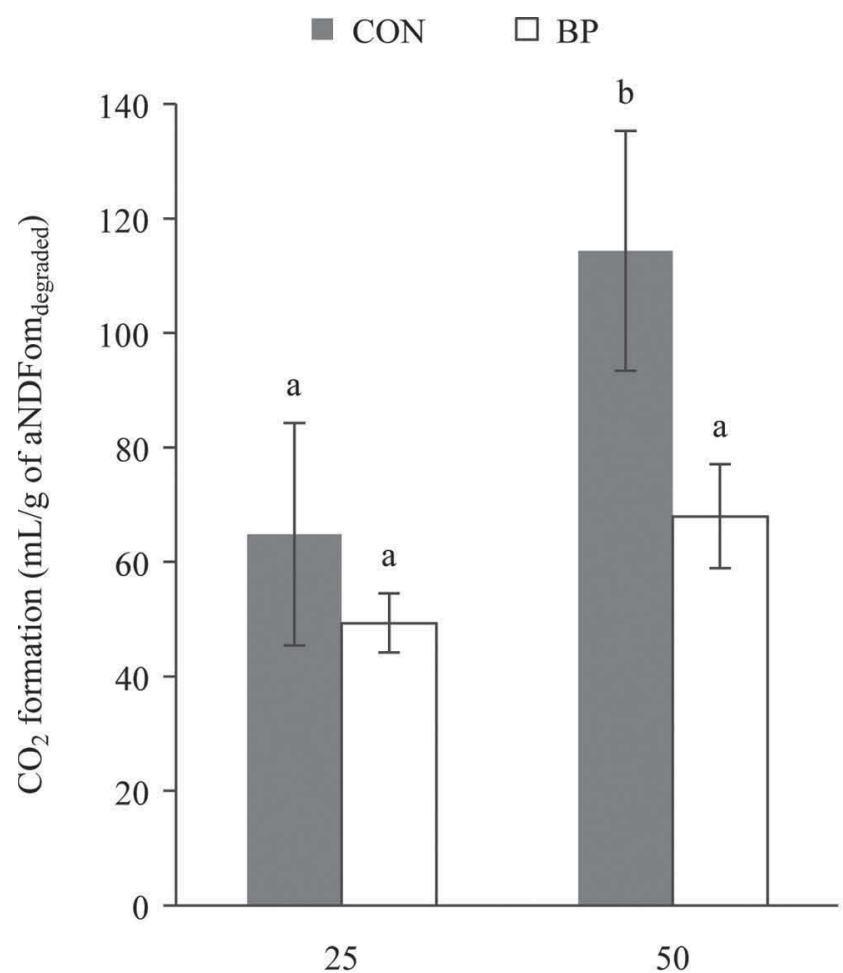

Concentrate level $(\%)$

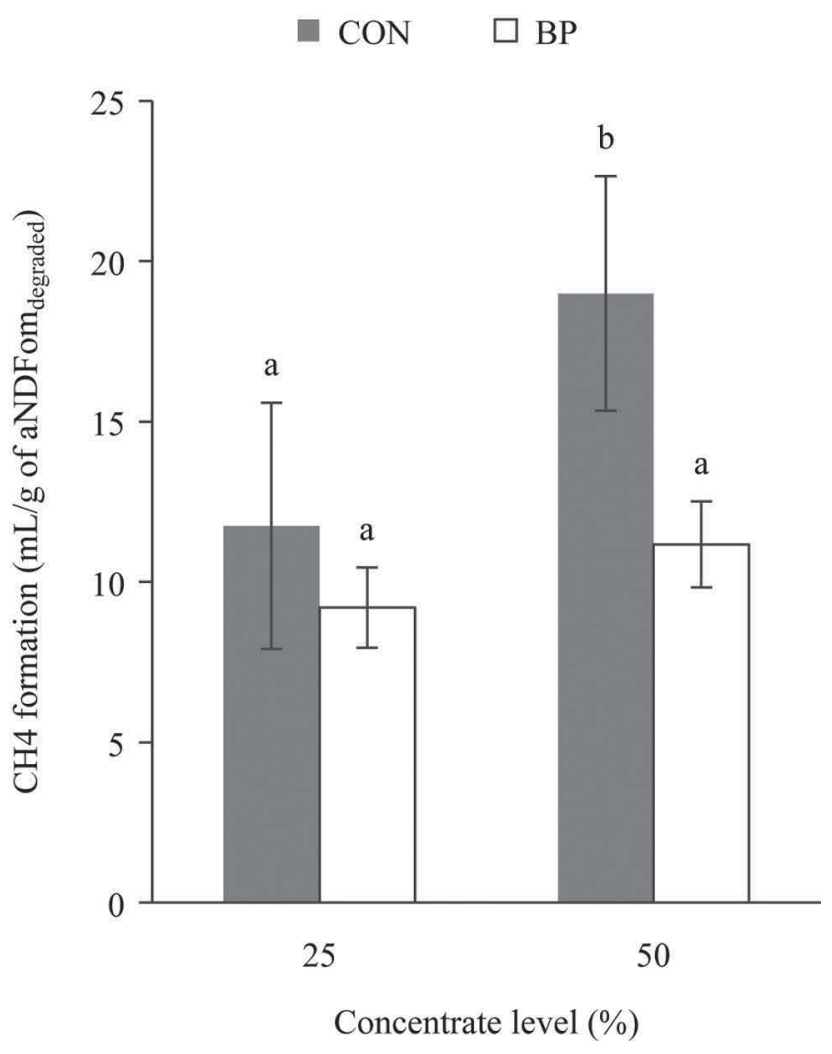

Figure 1. Mean $( \pm \mathrm{SD}) \mathrm{CO}_{2}$ (left) and $\mathrm{CH}_{4}$ (right) formation per gram of NDF corrected for ash degraded (aNDFom degraded) for diets containing control concentrate mixture $(\mathrm{CON})$ or by-product concentrate mixture $(\mathrm{BP})$. Columns not sharing the same letter (a,b) are different at $P$ $<0.05$. 
Table 3. Effects of concentrate type and level ( 25 or $50 \%)$ on short-chain fatty acid (SCFA) composition in fermenter fluid ( $\mathrm{n}=6$ per treatment, averages of $\mathrm{d} 6-10)^{1}$

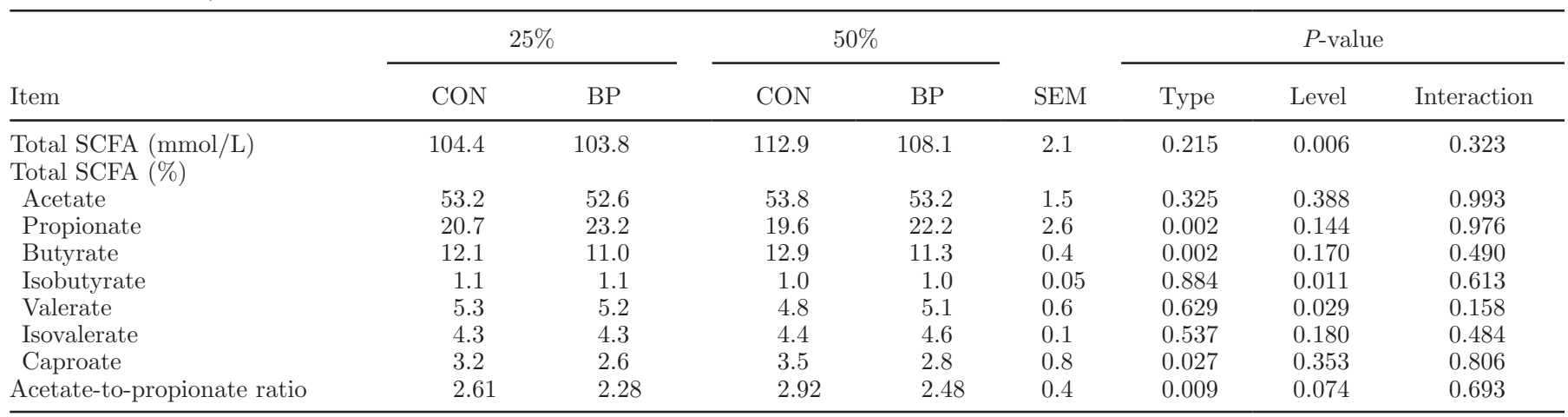

${ }^{1}$ Concentrate type: $\mathrm{CON}=$ control concentrate $\mathrm{BP}=$ by-product concentrate.

\section{Fermenter Fluid Microbiota}

Results of the PCR analysis are shown in Table 4. Concentrate type showed no effects on total gene copies per milliliter of total bacteria, protozoa, methanogens, or anaerobic fungi. However, occurrence of the genus Prevotella was elevated for $\mathrm{BP}$ as compared with CON, with more distinct effects at the $50 \%$ concentrate level. A higher number of gene copies of protozoa was found at the $50 \%$ concentrate level when compared with the
$25 \%$ level, whereas occurrence of methanogens and anaerobic fungi was reduced with the $50 \%$ concentrate level compared with the $25 \%$ concentrate level. Concentrate level also strongly influenced the bacterial composition. At 50\% concentrates, genus Prevotella showed greater abundance, whereas proportions of Ruminococcus albus, Butyrivibrio fibrisolvens, and Selenomonas ruminantium decreased. Megasphaera elsdenii numbers were only just above the detection limit of $10^{3}$ gene copies per milliliter, and therefore data were
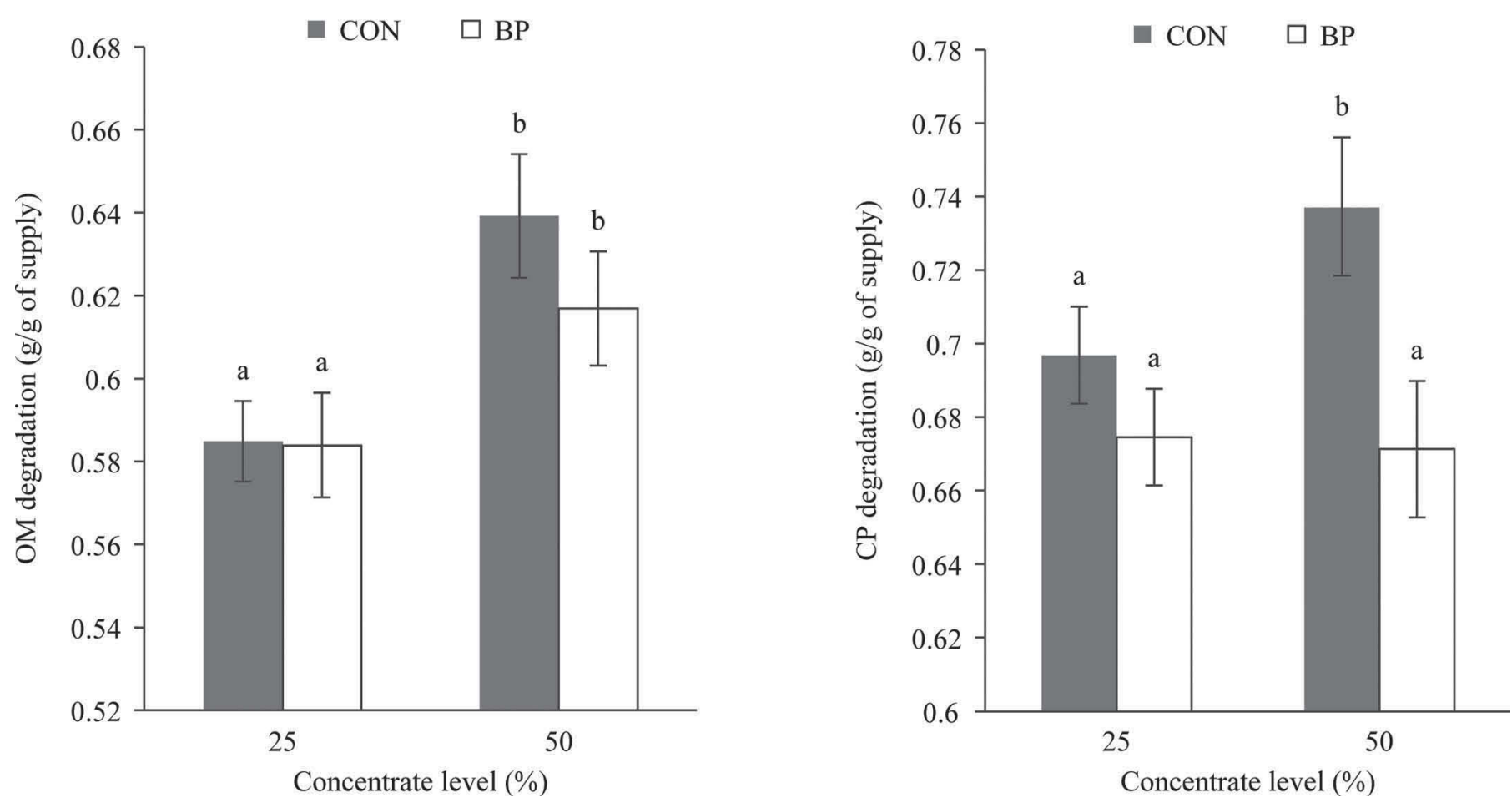

Figure 2. Mean $( \pm \mathrm{SD}) \mathrm{OM}$ and $\mathrm{CP}$ degradation for diets containing control concentrate mixture $(\mathrm{CON})$ or by-product concentrate mixture (BP). Columns not sharing the same letter $(\mathrm{a}, \mathrm{b})$ are different at $P<0.05$. 
Table 4. Effects of concentrate type and level (25 or 50\%) on fermenter fluid microbiota $(\mathrm{n}=6 \text { per treatment, averages of } \mathrm{d} 6-10)^{1}$

\begin{tabular}{|c|c|c|c|c|c|c|c|c|}
\hline Item & \multicolumn{2}{|c|}{$25 \%$} & \multicolumn{2}{|c|}{$50 \%$} & SEM & \multicolumn{3}{|c|}{$P$-value } \\
\hline \multicolumn{9}{|l|}{ Abundance $\left(\log _{10}\right.$ gene copies $\left./ \mathrm{mL}\right)$} \\
\hline Total protozoa & 6.74 & 6.45 & 7.06 & 6.88 & 0.13 & 0.050 & 0.004 & 0.664 \\
\hline Total methanogens & 6.93 & 6.91 & 6.81 & 6.73 & 0.13 & 0.449 & 0.029 & 0.630 \\
\hline Anaerobic fungi & 6.22 & 6.34 & 6.16 & 6.14 & 0.10 & 0.218 & 0.001 & 0.059 \\
\hline \multicolumn{9}{|c|}{ Bacterial composition (\% of total bacteria) } \\
\hline Ruminococcus albus & 0.68 & 0.69 & 0.42 & 0.38 & 0.08 & 0.835 & $<0.001$ & 0.702 \\
\hline Butyrivibrio fibrisolvens & 0.13 & 0.14 & 0.09 & 0.08 & 0.02 & 0.961 & 0.018 & 0.750 \\
\hline Selenomonas ruminantium & 0.54 & 0.52 & 0.39 & 0.37 & 0.04 & 0.533 & $<0.001$ & 0.943 \\
\hline Coverage of total bacteria $(\%)$ & 54.83 & 64.27 & 59.92 & 91.78 & 12.65 & $<0.001$ & 0.003 & 0.032 \\
\hline
\end{tabular}

${ }^{1}$ Concentrate type: $\mathrm{CON}=$ control concentrate; $\mathrm{BP}=$ by-product concentrate.

not shown. Correlation analyses among major results indicated positive correlations between total numbers of methanogens and anaerobic fungi $(\mathrm{r}=0.63, P=$ $0.001, \mathrm{n}=24)$ and methanogens and B. fibrisolvens $(\mathrm{r}$ $=0.64, P<0.001, \mathrm{n}=24)$.

\section{DISCUSSION}

\section{Concentrate Type}

The most pronounced differences in the chemical composition between the 2 concentrate types were in fiber, fat, and starch content. Increasing the dietary fat or starch content has been recently reviewed as a promising strategy to reduce enteric methane emissions from ruminants (Martin et al., 2010; Grainger and Beauchemin, 2011). However, despite differences in the fat content between the 2 diets, we did not observe differences in methane production. It can be assumed that the differences in the total dietary fat content between the diets were too small to affect methane production, because a decrease of only $3.8 \% \mathrm{CH}_{4}$ per percent of additional fat, as well as a strong dependence on the nature of the added fat, have been reported for in vivo studies (Martin et al., 2010). It is also possible that the higher fiber and lower starch content in the BP diets compensated the possible positive effects on methane emissions. In general, starch fermentation favors propionate production, which presents an alternative hydrogen sink to methanogenesis, whereas fiber promotes acetate production (Murphy et al., 1982) resulting in an increased acetate-to-propionate ratio when starch content decreases. However, in contrast to these known interrelations, we observed a lower acetate-to-propionate ratio for BP. A possible explanation for this might be the type of fiber in BP. Compared with CON, the aNDFom degradation was higher for the BP diets. This suggests that the BP diets contained more easily fermentable fiber, such as hemicellulose, which is assumed to stimulate propionate production too (Marounek et al., 1985).

One of the main components of hemicelluloses are xylans (Scheller and Ulvskov, 2010). Among others, feeds, such as sunflower hulls and corn hulls or brans, are known to contain high amounts of xylans (Ebringerova and Heinze, 2000). Thus, we assumed that the $\mathrm{BP}$ diets included more xylans, which are known to serve as substrates for bacteria belonging to the genus Prevotella. Besides starch, sugars, and xylans, pectins are also known substrates for these bacteria (Russell and Rychlik, 2001). Pectins are important components of sugar beet pulp (Drochner et al., 2004), which was higher in our BP diets. The higher levels of these fermentable fibers likely supported the higher abundance of the genus Prevotella in the BP diets. However, it should be considered when comparing treatment effects on bacterial genera that amplification results from quantitative $\mathrm{PCR}$ for the $16 \mathrm{~S}$ rRNA gene may be biased due to diverging numbers of copies of the target gene within the 16S rRNA gene between strains (Stevenson and Weimer, 2007). Due to their ability to produce end products other than lactate from the fermentation of starch, Prevotella spp. have recently been suggested as potential probiotics during SARA (Khafipour et al., 2009; Chiquette et al., 2012). Thus, the $\mathrm{BP}$ mixture might have potential to alleviate the risk of rumen disorders compared with the CON mixture. Fermentation products of the genus Prevotella are succinate, acetate, formate, and propionate (Russell and Rychlik, 2001). Succinate can be used to produce propionate (Strobel, 1992; Flint, 1997); therefore, the 
higher abundance of Prevotella is another explanation for the higher propionate concentration in BP diets. As the only major glucogenic SCFA, propionate can help to improve the energy balance and decrease the risk for metabolic disorders of cows in early lactation (Van Knegsel et al., 2007).

The lower concentration of butyrate for the BP diets is in agreement with Marounek et al. (1985), who reported low production of butyrate from hemicelluloses and pectins. Limited information is available on the role of caproate in the rumen metabolism. Caproate is a ketogenic SCFA (Kristensen and Harmon, 2005) and has been shown to inhibit gluconeogenesis from propionate in isolated sheep hepatocytes (Chow and Jesse, 1992). Our observed negative correlation between propionate and caproate and the positive correlation between acetate and caproate is in agreement with Durix et al. (1991), who found an increased caproate formation accompanied by an increase in the acetate-to-propionate ratio when ethanol was added in a Rusitec experiment. Caproate is formed during the secondary fermentation of the substrates ethanol and either acetate or butyrate (Ding et al., 2010), which supports the correlation we found between acetate and caproate, and the lower concentrations of butyrate might also account partly for the lower concentration of caproate for the BP diets. Ethanol levels are increased in the rumen fluid of cattle fed a diet with large amounts of starch, and also when the rumen environment tends to acidotic conditions (Saleem et al., 2012). Ethanol was not measured in this study, but it is probable that the starch-rich concentrate increased ethanol production in the rumen fluid, which led to more caproate in the CON diets. The role of caproate in rumen metabolism warrants further research.

The tendency for lower degradation of OM for the $\mathrm{BP}$ diets can be explained by the higher fiber content, as fiber is known to reduce digestibility in vitro and in vivo (Getachew et al., 2004, Huhtanen et al., 2009). In addition, the higher fat content of the BP diets could partly account for the lower degradation of the OM, because OM digestibility decreases linearly with increased dietary fat content (Patra, 2013). However, increased dietary fat is often considered to decrease especially fiber digestibility (NRC, 2001; Patra, 2013), which was not the case in our study, where aNDFom degradation was higher in the BP diets. Therefore, it is likely that the differences in the fat content between the treatments were not high enough to adversely affect degradation. As described previously, the higher aNDFom degradation is most likely the result of a higher proportion of highly degradable fiber (e.g., hemicellulose) in the BP diets; beet pulp as a major source of aNDFom in BP is known to contain highly digestible fiber (Durand et al., 1988; Getachew et al., 2004).

\section{Concentrate Level}

The effect of the concentrate level on ruminal fermentation has been investigated in earlier studies (e.g., Agle et al., 2010; Ametaj et al., 2010). However, by replacing CON entirely with BP at 2 different concentrate levels, we applied novel conditions. High concentrate levels are known to decrease ruminal $\mathrm{pH}$ and create unfavorable environmental conditions in the rumen (Ametaj et al., 2010). However, due to a continuous infusion of artificial saliva, $\mathrm{pH}$ is usually maintained at a normal and constant level in Rusitec systems (Hristov et al., 2012). Although we observed a slight but significant reduction in $\mathrm{pH}$ for the $50 \%$ concentrate level, $\mathrm{pH}$ always remained within an optimal range and therefore it is unlikely that it impaired the fermentation or microbiota in any way. Ammonia concentrations showed a strong tendency to be lower for the high-concentrate diet. This is in agreement with Hristov et al. (2001) and Agle et al. (2010), who observed lower ruminal ammonia concentrations when higher proportions of concentrates were fed. A possible explanation for the lower ammonia concentration is likely the higher availability of fermentable carbohydrates (e.g., starch), which serve as an energy source for bacteria, resulting in increased N uptake by the bacteria (Hristov et al., 2001; Bach et al., 2005; Agle et al., 2010). A better incorporation of ammonia $\mathrm{N}$ with increasing concentrate levels likely led to an increased protozoal abundance, observed when $50 \%$ concentrates were used. Conversely, the inclusion of $50 \%$ concentrate increased the dietary starch, which is likely the cause of the higher protozoa abundance, because in addition to bacteria, starch is an important substrate for protozoa (Dennis et al., 1983; Van Soest 1994).

In our study, at the $50 \%$ concentrate level, the fiber content of the diet was reduced and this resulted in decreased gene copy numbers of the fibrolytic anaerobic fungi, $R$. albus and B. fibrisolvens. In addition, numbers of $S$. ruminantium, a bacterium considered to be also involved in fiber degradation (Koike and Kobayashi, 2009) and another $\mathrm{H}_{2}$ producer (Russell and Rychlik, 2001), were reduced with $50 \%$ concentrate. This lower abundance of $\mathrm{H}_{2}$-producing microorganisms, making less substrate for methanogenesis, was probably the reason for the decrease in methanogens with $50 \%$ concentrate. This assumption is also supported by positive correlations between total numbers of methanogens and anaerobic fungi or B. fibrisolvens. Despite decreased numbers of methanogens, however, methane 
production did not differ between concentrate levels, supporting previous findings that not the methanogen abundance but rather their diversity is more influential to enteric methane emissions (Mohammed et al., 2011).

In vivo studies have repeatedly reported that higher concentrate levels can negatively affect whole-diet digestibility due to a lower digestion of potentially digestible fiber (Nousiainen et al., 2009). A tendency for decreased aNDFom degradation was also observed in our study, probably due to the lower abundance of fibrolytic microorganisms. However, this effect was too small to have affected whole-diet degradability. The degradation of $\mathrm{OM}, \mathrm{CP}$, and ether extract at the $50 \%$ concentrate level was higher, which can be explained with the lower fiber and higher starch contents, favoring digestibility (Van Soest, 1994).

\section{CONCLUSIONS}

Under in vitro conditions, the substitution of common concentrates with a mixture of industrial byproducts did not indicate negative effects with regard to ruminal fermentation profile, nutrient degradation, and microbial community composition. The fact that the $\mathrm{BP}$ diets, which contain less starch and more fiber, led to no decrease in the total SCFA production, but to higher concentration of the glycogenic propionate and to a higher occurrence of bacteria belonging to genus Prevotella as compared with CON diets, is remarkable. It suggests that these by-products might even have potential to stimulate propionate formation and gluconeogenesis in dairy cows, a process which is very important in particular during early lactation. However, studies on the relationship between microbial and fermentation patterns of Rusitec and those found in vivo are limited and, therefore, further in situ or in vivo trials are needed to verify our findings.

\section{ACKNOWLEDGMENTS}

The authors thank the Austrian Federal Ministry of Agriculture, Forestry, Environment and Water Management (Vienna, Austria), Bio Austria (Linz, Austria), the Salzburger Landesregierung (Salzburg, Austria), Raiffeisenverband Salzburg (Salzburg, Austria), and the Werner Lampert Beratungsges.m.b.H. (Vienna, Austria) for funding this research. Furthermore, we thank Kathleen Knaus (WU, Vienna University of Economics and Business, Vienna, Austria) for editing assistance, Astrid Lengauer and Behzad Khorrami for their essential assistance during the experiment, as well as Anita Dockner, Melanie Wild, Martin Finsterböck, and Sabine Leiner (Institute of Animal Nutrition and
Functional Plant Compunds, Vetmeduni, Vienna) for performing laboratory analyses.

\section{REFERENCES}

Agle, M., A. N. Hristov, S. Zaman, C. Schneider, P. M. Ndegwa, and V. K. Vaddella. 2010. Effect of dietary concentrate on rumen fermentation, digestibility, and nitrogen losses in dairy cows. J. Dairy Sci. 93:4211-4222.

Ametaj, B. N., Q. Zebeli, F. Saleem, N. Psychogios, M. J. Lewis, S. M. Dunn, J. G. Xia, and D. S. Wishart. 2010. Metabolomics reveals unhealthy alterations in rumen metabolism with increased proportion of cereal grain in the diet of dairy cows. Metabolomics 6:583-594

Bach, A., S. Calsamiglia, and M. D. Stern. 2005. Nitrogen metabolism in the rumen. J. Dairy Sci. 88:E9-E21.

Bradford, G. E. 1999. Contributions of animal agriculture to meeting global human food demand. Livest. Prod. Sci. 59:95-112.

Chiquette, J., M. J. Allison, and M. Rasmussen. 2012. Use of Prevotella bryantii $25 \mathrm{~A}$ and a commercial probiotic during subacute acidosis challenge in midlactation dairy cows. J. Dairy Sci. 95:5985-5995.

Chow, J. C., and B. W. Jesse. 1992. Interactions between gluconeogenesis and fatty-acid oxidation in isolated sheep hepatocytes. J. Dairy Sci. 75:2142-2148.

Denman, S. E., and C. S. McSweeney. 2006. Development of a realtime PCR assay for monitoring anaerobic fungal and cellulolytic bacterial populations within the rumen. FEMS Microbiol. Ecol. 58:572-582.

Dennis, S. M., M. J. Arambel, E. E. Bartley, and A. D. Dayton. 1983. Effect of energy concentration and source of nitrogen on numbers and types of rumen protozoa. J. Dairy Sci. 66:1248-1254.

Ding, H. B., G. Y. A. Tan, and J. Y. Wang. 2010. Caproate formation in mixed-culture fermentative hydrogen production. Bioresour. Technol. 101:9550-9559.

Drochner, W., A. Kerler, and B. Zacharias. 2004. Pectin in pig nutrition, a comparative review. J. Anim. Physiol. Anim. Nutr. (Berl.) 88:367-380.

Durand, M., C. Dumay, P. Beaumatin, and M. T. Morel. 1988. Use of the rumen simulation technique (Rusitec) to compare microbial digestion of various by-products. Anim. Feed Sci. Technol. 21:197-204.

Durix, A., C. Jeanblain, H. P. Sallmann, and J. P. Jouany. 1991. Use of a semicontinuous culture system (Rusitec) to study the metabolism of ethanol in the rumen and its effects on ruminal digestion. Can. J. Anim. Sci. 71:115-123.

Ebringerova, A., and T. Heinze. 2000. Xylan and xylan derivativesBiopolymers with valuable properties. 1-Naturally occurring xylans structures, procedures and properties. Macromol. Rapid Commun. 21:542-556.

Ertl, P., Q. Zebeli, W. Zollitsch, and W. Knaus. 2015. Feeding of byproducts completely replaced cereals and pulses in dairy cows, and enhanced edible feed conversion ratio. J. Dairy Sci. 98:1225-1233.

Federal Ministry of Health. 2004. BGBI. II Nr. 485/2004: 1. Tierhaltungsverordnung. Accessed Apr. 30, 2015. https://www.ris.bka. gv.at/GeltendeFassung.wxe?Abfrage=Bundesnormen\&Gesetzesnu mmer $=20003820$

Flint, H. J. 1997. The rumen microbial ecosystem-Some recent developments. Trends Microbiol. 5:483-488.

Getachew, G., P. H. Robinson, E. J. DePeters, and S. J. Taylor. 2004. Relationships between chemical composition, dry matter degradation and in vitro gas production of several ruminant feeds. Anim. Feed Sci. Technol. 111:57-71.

Grainger, C., and K. A. Beauchemin. 2011. Can enteric methane emissions from ruminants be lowered without lowering their production? Anim. Feed Sci. Technol. 166-67:308-320.

Hall, M. B., and L. E. Chase. 2014. Responses of late-lactation cows to forage substitutes in low-forage diets supplemented with byproducts. J. Dairy Sci. 97:3042-3052.

Hristov, A. N., M. Ivan, L. M. Rode, and T. A. McAllister. 2001. Fermentation characteristics and ruminal ciliate protozoal popula- 
tions in cattle fed medium- or high-concentrate barley-based diets. J. Anim. Sci. 79:515-524.

Hristov, A. N., C. Lee, R. Hristova, P. Huhtanen, and J. L. Firkins. 2012. A meta-analysis of variability in continuous-culture ruminal fermentation and digestibility data. J. Dairy Sci. 95:5299-5307.

Huhtanen, P., M. Rinne, and J. Nousiainen. 2009. A meta-analysis of feed digestion in dairy cows. 2. the effects of feeding level and diet composition on digestibility. J. Dairy Sci. 92:5031-5042.

Khafipour, E., S. C. Li, J. C. Plaizier, and D. O. Krause. 2009. Rumen microbiome composition determined using two nutritional models of subacute ruminal acidosis. Appl. Environ. Microbiol. 75:7115-7124.

Khiaosa-Ard, R., B. U. Metzler-Zebeli, S. Ahmed, A. Muro-Reyes, K. Deckardt, R. Chizzola, J. Böhm, and Q. Zebeli. 2015. Fortification of dried distillers grains plus solubles with grape seed meal in the diet modulated methane mitigation and rumen microbiota in Rusitec. J. Dairy Sci. 98:2611-2626.

Klevenhusen, F., K. Deckardt, Ö. Sizmaz, S. Wimmer, A. MuroReyes, R. Khiaosa-Ard, R. Chizzola, and Q. Zebeli. 2015. Effects of black seed oil and Ferula elaeochytris supplementation on ruminal fermentation as tested in vitro with the rumen simulation technique (Rusitec). Anim. Prod. Sci. 55:736-744. http://dx.doi. org/10.1071/AN13332.

Koike, S., and Y. Kobayashi. 2009. Fibrolytic rumen bacteria: Their ecology and functions. Asian-australas. J. Anim. Sci. 22:131-138.

Kristensen, N. B., and D. L. Harmon. 2005. Effects of adding valerate, caproate, and heptanoate to ruminal buffers on splanchnic metabolism in steers under washed-rumen conditions. J. Anim. Sci. 83:1899-1907.

Li, M., G. B. Penner, E. Hernandez-Sanabria, M. Oba, and L. L. Guan. 2009. Effects of sampling location and time, and host animal on assessment of bacterial diversity and fermentation parameters in the bovine rumen. J. Appl. Microbiol. 107:1924-1934.

Marounek, M., S. Bartos, and P. Brezina. 1985. Factors influencing the production of volatile fatty-acids from hemicellulose, pectin and starch by mixed culture of rumen microorganisms. Z. Tierphysiol. Tierernahr. Futtermittelkd. 53:50-58.

Martin, C., D. P. Morgavi, and M. Doreau. 2010. Methane mitigation in ruminants: From microbe to the farm scale. Animal 4:351-365.

Martínez, M. E., M. J. Ranilla, M. L. Tejido, C. Saro, and M. D. Carro. 2010. Comparison of fermentation of diets of variable composition and microbial populations in the rumen of sheep and Rusitec fermenters II. Protozoa population and diversity of bacterial communities. J. Dairy Sci. 93:3699-3712.

Metzler-Zebeli, B. U., S. Schmitz-Esser, F. Klevenhusen, L. Podstatzky-Lichtenstein, M. Wagner, and Q. Zebeli. 2013. Grain-rich diets differently alter ruminal and colonic abundance of microbial populations and lipopolysaccharide in goats. Anaerobe 20:65-73.

Mohammed, R., M. Zhou, K. M. Koenig, K. A. Beauchemin, and L. L. Guan. 2011. Evaluation of rumen methanogen diversity in cattle fed diets containing dry corn distillers grains and condensed tannins using PCR-DGGE and qRT-PCR analyses. Anim. Feed Sci. Technol. 166-167:122-131.
Mowrey, A., M. R. Ellersieck, and J. N. Spain. 1999. Effect of fibrous by-products on production and ruminal fermentation in lactating dairy cows. J. Dairy Sci. 82:2709-2715.

Murphy, M. R., R. L. Baldwin, and L. J. Koong. 1982. Estimation of stoichiometric parameters for rumen fermentation of roughage and concentrate diets. J. Anim. Sci. 55:411-421.

Muyzer, G., E. C. Dewaal, and A. G. Uitterlinden. 1993. Profiling of complex microbial-populations by denaturing gradient gelelectrophoresis analysis of polymerase chain reaction-amplified genes-coding for 16 s ribosomal-RNA. Appl. Environ. Microbiol. $59: 695-700$

Nousiainen, J., M. Rinne, and P. Huhtanen. 2009. A meta-analysis of feed digestion in dairy cows. 1 . The effects of forage and concentrate factors on total diet digestibility. J. Dairy Sci. 92:5019-5030.

NRC. 2001. Nutrient Requirements of Dairy Cattle. 7th rev. ed. Natl. Acad. Press, Washington, DC.

Patra, A. K. 2013. The effect of dietary fats on methane emissions, and its other effects on digestibility, rumen fermentation and lactation performance in cattle: A meta-analysis. Livest. Sci. 155:244-254.

Petri, R. M., T. Schwaiger, G. B. Penner, K. A. Beauchemin, R. J. Forster, J. J. McKinnon, and T. A. McAllister. 2013. Changes in the rumen epimural bacterial diversity of beef cattle as affected by diet and induced ruminal acidosis. Appl. Environ. Microbiol. 79:3744-3755.

Prevot, S., J. Senaud, J. Bahatier, and G. Prensier. 1994. Variation in the composition of the ruminal bacterial microflora during the adaptation phase in an artificial fermentor (Rusitec). Zoolog. Sci. 11:871-878.

Russell, J. B., and J. L. Rychlik. 2001. Factors that alter rumen microbial ecology. Science 292:1119-1122.

Saleem, F., B. N. Ametaj, S. Bouatra, R. Mandal, Q. Zebeli, S. M. Dunn, and D. S. Wishart. 2012. A metabolomics approach to uncover the effects of grain diets on rumen health in dairy cows. J. Dairy Sci. 95:6606-6623.

Scheller, H. V., and P. Ulvskov. 2010. Hemicelluloses. Annu. Rev. Plant Biol. 61:263-289.

Soliva, C. R., and H. D. Hess. 2007. Measuring methane emission of ruminants by in vitro and in vivo techniques. Pages 13-15 in Measruing Methane Production from Ruminants. H. P. S. Makkar and P. E. Vercoe, ed. Springer, Dordrecht, the Netherlands.

Stevenson, D. M., and P. J. Weimer. 2007. Dominance of Prevotella and low abundance of classical ruminal bacterial species in the bovine rumen revealed by relative quantification real-time PCR Appl. Microbiol. Biotechnol. 75:165-174.

Strobel, H. J. 1992. Vitamin-B12-dependent propionate production by the ruminal bacterium Prevotella-Ruminicola-23. Appl. Environ. Microbiol. 58:2331-2333.

van Knegsel, A. T. M., H. van den Brand, J. Dijkstra, and B. Kemp. 2007. Effects of dietary energy source on energy balance, metabolites and reproduction variables in dairy cows in early lactation. Theriogenology 68:S274-S280

Van Soest, P. J. 1994. Nutritional Ecology of the Ruminant. 2nd ed. Cornell University Press, Ithaca, NY. 